\title{
ResearchOnline@JCU
}

This is the author-created version of the following work:

Krause, Amanda E., and North, Adrian C. (2016) Playlists and time perspective. Psychology of Music, 44 (5) pp. 1209-1218.

Access to this file is available from:

https://researchonline.jcu.edu.au/64288/

(C) The Author(s) 2016

Please refer to the original source for the final version of this work:

https://doi.org/10.1177/0305735616636210 


\begin{abstract}
Research on playlists has focused on how usage is related to technological and music industry variables, and the demographic characteristics of users. However, it seems reasonable to suspect a psychological component to playlist usage also. The present research considered an individual's propensity to devise and make use of playlists in terms of time perspective. Significant results indicate an emphasis on the time at hand while listening, so that playlist use has a present-orientated time perspective, rather than a future-oriented time perspective. The findings support other recent research illustrating that exercising control over everyday listening is an important aspect of musical behavior in present-day music listening.
\end{abstract}

Keywords: time perspective, playlists, music listening Running head: Playlists \& time perspective 
Playlists and Time Perspective

The technology of the late 20th century grouped individual pieces of music into collections that were accessed via CDs, vinyl records, or tapes and played sequentially for approximately 45-60 minutes. Newer technology and the digitization of music listening, however, have facilitated enhanced user choice. Listeners can select individual pieces, listen to idiosyncratic playlists based on any number of attributes (Molteni \& Ordanini, 2003), and to listen to pieces played at random via "shuffle". The present research focuses on playlists as a common selection method for listening (Komulainen, Karukka, \& Hakkila, 2010; Krause, 2010). Much of the work on playlists has focused on how their development is shaped by technological and music industry variables (e.g., Fields \& Lamere, 2010; Kamalzadeh, Baur, \& Möller, 2012; Stumpf \& Muscroft, 2011) or on the demographic characteristics of those who are less or more likely to use them (e.g., Baur, Büttgen, \& Butz, 2012; Brown, Geelhoed, \& Sellen, 2001; Krause, North, \& Hewitt, 2014). For example, research has considered the prominent features that listeners use when constructing playlists, considering elements such as tempo, mood, genre, and lyrical content (Fields \& Lamere, 2010; Stumpf \& Muscroft, 2011). Such work, which has been carried out typically by those interested in music information retrieval (MIR), does not consider theories in (music) psychology (Hu, 2010), with little, if any, consideration of the users themselves or their needs and motivations (Lee \& Cunningham, 2013). Only recently has a limited literature begun to be published that has adopted an explicitly psychological approach to playlist usage (e.g., Krause \& North, 2016). In particular, one psychological construct, the concept of (future and present) time perspective may be relevant to how people listen to music via playlists. Specifically, it might be 
expected that an orientation towards the present and/or future would influence an individual's propensity to devise and make use of playlists.

\section{Time Perspective}

Time perspective is an awareness that thoughts and behaviors in the present can have implications for future well-being, and addresses the extent to which an individual is concerned with the present moment and also with the future. Time perspective has been shown to affect a person's attention, decisions, and actions; and these time frames are used in understanding experienced events and in forming expectations for future events (Boniwell \& Zimbardo, 2004; Keough, Zimbardo, \& Boyd, 1999; Zimbardo \& Boyd, 1999).

A person's time perspective is stable over time (Boniwell \& Zimbardo, 2004; Laghi, Liga, Baumgartner, \& Baiocco, 2012). While a balanced time perspective allows individuals to adjust their perspective to the one that might be most suitable in a particular situation, people can instead have bias in their time perspective towards the present or the future (Keough et al., 1999). Those individuals who are more present-orientated tend not to worry about the past or experience anxiety concerning the future: they are instead rooted firmly in the present. Those who are more futureorientated, on the other hand, tend to use planning strategies and are effective at setting and achieving goals (Keough, et al., 1999): one's sense of purpose for the future guides one to engage in the present in activities that would be beneficial for future outcomes (McInerney, 2004; Seijts, 1998). Thus, time perspective provides a filter through which people make sense of their life experiences and shape their behaviors (Holman \& Zimbardo, 2009). 
A growing body of research considers time perspective and a range of related behaviors. For instance, associations have been found between a future-orientated time perspective and a range of health behaviors, such as substance use, abuse, and cessation (e.g., Adams, 2009; Apostolidis, Fieulaine, \& Soulè, 2006; Hall et al., 2012); coping with illness and disease (e.g., Mann, 2001); preventative health behaviors, such as sunscreen use (Orbell \& Kyriakaki, 2008); and participation in physical activity and exercise (e.g., Gellert, Ziegelmann, Lippke, \& Schwarzer, 2012; Hall \& Fong, 2003; Kahana, Kahana, \& Zhang, 2005). Time perspective is also related to environmental behaviors (e.g., Arnocky, Milfont, \& Nicol, 2014; CorralVerdugo, Fraijo-Sing, \& Pinheiro, 2006); academic achievement (Mello \& Worrell, 2006); goals and social relationships (Holman \& Zimbardo, 2009; Lang \& Carstensen, 2002); and personality (e.g., Dunkel \& Weber, 2010; Zhang \& Howell, 2011). Similarly, the relevance of time perspective to a range of psychological functioning has been illustrated by Lang and Carstensen (2002), who found that their participants' goals were congruent with their time perspective, and that this also related to their social networks.

Of greatest relevance to the present research, however, are findings concerning the relationship between time perspective and mood (e.g., Stolarski, Matthews, Postek, Zimbardo, \& Bitner, 2014). Stolarski, et al. (2014) confirmed that time perspective is related to current mood, as well as to the anticipation and recollection of mood. Furthermore, it appears that this occurs via processes associated with emotion-regulation specifically. Emotion-regulation, or the modulation one one's emotion, can also of course be accomplished through interaction with music. Several studies have demonstrated that music is used as a resource for individuals as they undertake other activities or otherwise to regulate 
their emotions and experiences (Batt-Rawden \& DeNora, 2005; DeNora, 2000; Lamont \& Greasley, 2009). Indeed, music's ability to influence mood is one of the more frequent reasons people give for listening (Garrido \& Schubert, 2015; Saarikallio, 2008).

However, the anticipation of future listening needs and planning one's listening is an aspect of music listening that has been neglected in research. Thus, the present study considers whether time perspective is related to playlist listening. Consideration of this is particularly timely: with the increased and commonplace use of digital technologies, consideration of everyday listening via playlists has considerable currency.

Playlists can be grouped into different categories, whether by mood, genre, specific artist, or activity, to note just a few of the possibilities (see Cunningham et al., 2006; Krause, 2010). They are often created for repeated use, sometimes in advance of their actual activation (Cunningham et al., 2006; Molteni \& Ordanini, 2003). Cunningham et al. (2006) argued that there is a difference in the effort needed to craft a playlist as opposed to listening via shuffle: playlists require planning in some way, as opposed to shuffle listening which prior research has suggested is used when the person in question is simply bored or has no strong preference regarding what is heard (e.g, Cunningham et al., 2006; Kibby, 2009; Leong et al., 2008). Such use of music - when music is used as a resource to accompany other activities or to regulate emotions - requires an element of pre-planning and/or a degree of concern with music at the precise moment of use. Moreover, it is possible that the creation and subsequent selection of playlists could be aligned with attempts to address particular needs (DeNora, 2000), and again these needs may be anticipated well in advance of the music being heard or only at the moment of use. Because of this, it is 
possible that a person's time perspective orientation affects their use of such a listening strategy. In addition to a tendency to create and/or listen to playlists as a way of accessing music, the relationship between time perspective and playlist listening could also be more nuanced: it could be that time perspective is related to specific types of playlists, such as those made to accompany specific situations or moods. Therefore, the present research addresses two main research questions:

RQ1: Does time perspective relate to an individual's tendency to listen to music via playlists? It is possible to make two competing hypotheses regarding this research question. One hypothesis is that that future time perspective will be related to a predilection to making particular types of playlists because this type of listening might represent the consequence of pre-planning. An alternative (and not necessarily mutually exclusive) possibility is that playlists reflect a present time perspective, so that their use reflects an immediate wish to address specific aspects of the immediate context of music listening and the individual's goals therein.

RQ2: Does time perspective relate to an individual's tendency to make different types of playlists defined in terms of genre, a mood, specific artist, or for use in specific situations/activities? This question allows for the consideration of time perspective to different types of playlists. It is possible to speculate that if, in answer to RQ1, future-orientated people are more likely to make playlists, it is possible that future time perspective is also associated with playlists constructed in anticipation for specific situations or for expressing particular moods, as a listener might have the forethought to plan ahead to want to hear certain music (via a playlist).

\section{Method}




\section{Participants}

Individuals were approached in person (at a local arts festival and on a university campus) and the study was advertised online. Mean responses to each variable were calculated for the paper- and web-based samples, and because the product-moment correlation between these data sets was .96 , the data sets were merged for subsequent analyses. Analyses were conducted using the data from 201 individuals from the UK. Ages ranged from 17-64 years $(M=21.87, M d n=20), 67.20 \%$ of the sample was female, and $22.40 \%$ of the participants had university qualifications. Participation was voluntary although some university students received coursework credit for their participation.

\section{Design and procedure}

Data was collected as a part of a larger study considering how people access and listen to music (Krause \& North, 2016), and the present study employed only the data concerning time perspective and playlists. Specifically, participants were asked to complete a questionnaire that included questions about themselves and their everyday music listening habits. Participants were provided with instructions for completion in advance and were then thanked and debriefed upon completion.

Individuals stated how likely, on a seven-point scale $(1=$ not at all, $7=$ entirely), they were to listen to music via playlists and to make each of five types of playlists derived from Krause's (2010) study, namely those based on “a music artist/ group," "a genre," "a specific situation or activity," “a feeling/ emotion/ mood," and “time (holiday, occasion, season, etc.)." Additionally, participants were asked about making playlists for eight different situations. These situations were chosen to represent a range of everyday situations that have featured in previous research 
(Krause \& North, 2014; North \& Hargreaves, 1996): they were "a house party with friends," "commuting on public transportation," "while doing the washing up/ironing," "before going to sleep," "a posh cocktail reception," "after a long day of work," "a wedding," and "while jogging with an mp3 player."

The Zimbardo Time Perspective Inventory (ZTPI short form; Keough et al., 1999; Zimbardo, Keough, \& Boyd, 1997) was employed to measure participants’ time perspective. It consists of 22 items, with 13 items representing a 'future time perspective' (hereafter, “FTP”) scale and nine items representing a 'present time perspective' (hereafter, “PTP”) scale. For instance, items such as, “I don’t do things that will be good for me if they don't feel good now" address PTP, while items such as, "I believe that a person's day should be planned ahead each morning" address FTP. Each participant received a FTP and PTP score, which were used in the analyses. This scale has demonstrated reasonable internal reliability and test-retest reliability across samples (Keough et al., 1999; Zimbardo et al., 1997), and is easy to use (Keough et al., 1999; Zimbardo et al., 1997). Cronbach's alphas for FTP and PTP in the present study were .72 and .60 respectively, similar to the values reported previously (e.g., Keough et al., 1999; Zimbardo et al., 1997).

\section{Results}

\section{Participants}

As shown in Table 1, playlists are used commonly ( $M=4.60$ on a seven-point scale). However, the means for the different types of playlists suggest varying popularity across the different types: playlists for feelings/moods and situations /activities demonstrated higher means suggesting more frequent use (see Table 1). Moreover, 
regarding the situations, playlists made for house parties and while jogging received the highest means while playlists made for weddings and cocktails parties receive the lowest means (see Table 1). The correlations shown in Table 1 also indicate that younger individuals are more likely to make playlists.

-Table 1 about here-

\section{Frequency of playlist listening}

Two Pearson's correlations $(\alpha=.025)$ analyzed the association between the rating of how often participants listened to music via playlists and each of PTP and FTP respectively (RQ1). Neither PTP nor FTP were significantly correlated with listening to music by playlist (PTP: $r(199)=.09, p=.170$; FTP: $r(199)=.15, p=.037$ ).

\section{Types of playlists}

Two hierarchical multiple regression analyses $(\alpha=.025)$ examined the extent to which FTP and PTP respectively were associated with constructing the different types of playlists and use of playlists in different settings and locations (RQ2). In each analysis, the different types of playlist were entered as the first block of predictor variables, and the ratings assigned to the different settings and locations were entered as the second block of variables. Statistical assumptions were checked for both analyses, and because the Mahalanobis distance exceeded the critical $\chi^{2}$ value $(\mathrm{df}=13$ $(\alpha=.001)=34.53)$, two cases were removed and each analysis was re-run. The analysis concerning FTP was non-significant, $R^{2}=.11$, adjusted $R^{2}=.04, F(13,185)$ $=1.71, p=.062, f^{2}=.120$. 
However, in combination, the different playlist types accounted for a significant $16.3 \%$ of the variance in PTP scores $\left(R^{2}=.21\right.$, adjusted $R^{2}=.16, F(13$, $\left.185)=3.86, p<.001, f^{2}=.271\right)$, and both the different types of playlists and the different settings and locations were able to significantly predict PTP scores. Details concerning individual variables are presented in Table 2 . The results indicate that, of the five types of playlists, PTP was positively associated with making playlists for specific activities/ situations. Moreover, PTP was positively associated with the propensity to create a playlist specifically for use before going to sleep and negatively associated with the propensity to create a playlist to use while jogging with an mp3 player.

-Table 2 about here -

\section{Discussion}

Playlists afford users the ability to design what music they hear, and by doing so listeners can tailor music listening to a specific situation. The absence of a positive correlation between FTP and listening to music via playlist suggests that there is not a link between playlist listening and possessing a strong future time perspective. Playlist listening is not necessarily associated with planning ahead regarding how one will access music (e.g., creating playlists in anticipation for one's listening needs).

The correlation between PTP and how often one listens to music via playlists was also non-significant. However, the significant regression analysis concerning PTP does indicate that playlist use is associated with a present-orientated time perspective, rather than a future-oriented time perspective. In particular, the results indicate that 
PTP is positively associated with making playlists that are based on a specific activity or situation. The use of a music playlist in the context of an activity or situation clearly reflects an attempt to enhance that activity or assist in context-dependent attempts to reach a goal. Therefore, it seems that playlist use is tied to a presentbased, or a "live in the moment" type of listening use.

With regard to the significant results concerning PTP and for playlist use prior to going to sleep, one possibility is that a person prioritizes not having to make listening decisions (while still wanting to have a choice in what is heard). Thus a playlist facilitates the listener's perception of him/herself exerting choice, but in a predetermined way that would not hinder attempts to drift off to sleep; and this possible explanation is consistent with previous research that has supported using music as a sleep aid (e.g., de Niet, Tiemens, Lendemeijer, \& Hutschemaekers, 2009).

While the means indicate that there was a high propensity to create playlists based on a feeling/ mood (Cunningham et al., 2006; Krause, 2010), this type of playlist was not a significant predictor of time perspective in the regression analysis. While previous research indicates that music is used for emotion regulation, it does not necessarily do so via playlist listening. It is possible that people select their music differently for different intended uses, although additional research is required to consider this possibility.

By considering playlists, the present research supports the recent body of findings that exercising control over everyday listening is an important aspect of musical behavior in the modern world (e.g., Kamalzadeh et al., 2012; Krause et al., 2014). Digital technology provides an opportunity for listeners to exercise greater control than hitherto over their listening, either in the moment itself or on a planned basis that reflects expected future use. The results reported here indicate that music 
use in the moment is related more closely to playlist use than are planned uses that reflect intended future listening.

\section{Limitations and future research}

Of course, the prevalence of newer technologies in music listening affords listeners a wide variety of user control options. While the sophistication of the technology makes it difficult to study all possible uses within a single methodology, one notable limitation of the present work is that it considered playlist listening broadly, which may be insufficient to capture the full reality of everyday listening. It is possible to make a personalized playlist for later listening, make use of a playlist crafted by someone else, or make a playlist at any given moment. This could explain why both FTP and PTP were not significantly correlated with scores on the item concerning the habit of listening via playlists. Further, it is possible for a listener to shuffle a playlist, which opens up the question of whether listeners are making multiple control-based decisions or one single decision. Thus, future research should continue to tease out and address the detail and psychological underpinning of how people access and select music.

Moreover, it would be interesting for future research to also consider time perspective and the specific functions of music in everyday life. As the current results indicated, PTP was associated with playlists for certain activities or situations. While music may accompany different activities, there are many different uses, or functions, of music listening in everyday life. It is possible, for instance, that time orientations may be related differently to using music for cognitive purposes (which perhaps reflects a future orientation) rather than emotional purposes (perhaps reflecting a present orientation). Additionally, this time-related aspect of usage of music technology 
should be considered when developing theoretical explanations of everyday experiences of music. Thus, future research should continue to explore how psychological constructs such as time perspective relate to people's musical behaviors in the digital era. 


\section{References}

Adams, J. (2009). The role of time perspective in smoking cessation amongst older English adults. Health Psychology, 28(5), 529-534. doi: 10.1037/a0015198

Apostolidis, T., Fieulaine, N., \& Soulè, F. (2006). Future time perspective as predictor of cannabis use: Exploring the role of substance perception among French adolescents. Addictive Behaviors, 31(12), 2339-2343.

doi:10.1016/j.addbeh.2006.03.008

Arnocky, S., Milfont, T. L., \& Nicol, J. R. (2014). Time perspective and sustainable behavior: Evidence for the distinction between consideration of immediate and future consequences. Environment and Behavior, 46(5), 556-582.

doi:10.1177/0013916512474987

Batt-Rawden, K. B., \& DeNora, T. (2005). Music and informal learning in everyday life. Music Education Research, 7(3), 289-304.

doi:10.1080/14613800500324507

Baur, D., Büttgen, J., \& Butz, A. (2012). Listening factors: A large-scale principal components analysis of long-term music listening histories. Proceedings of the SIGCHI Conference on Human Factors in Computing Systems, 1273-1276.

New York, NY: ACM. doi: 10.1145/2207676.2208581

Boniwell, I., \& Zimbardo, P. G. (2004). Balancing one's time perspective in pursuit of optimal functioning. In P. A. Linley \& S. Joseph (Eds.), Positive psychology in practice (pp. 165-178). Hoboken, NJ: Wiley.

Brown, B., Geelhoed, E., \& Sellen, A. (2001). The use of conventional and new music media: Implications for future technologies. Paper presented at the Interact 2001, Tokyo, Japan. 
Corral-Verdugo, V., Fraijo-Sing, B., \& Pinheiro, J. Q. (2006). Sustainable behavior and time perspective: Present, past and future orientations and their relationship with water conservation behavior. Interamerican Journal of Psychology, 40(2), 139-147.

Cunningham, S. J., Bainbridge, D., \& Falconer, A. (2006). 'More of an art than a science:' Supporting the creation of playlists and mixes. Paper presented at the the Seventh International Conference on Music Information Retrieval (ISMIR 2006), University of Victoria: Victoria, Canada.

de Niet, G., Tiemens, B., Lendemeijer, B., \& Hutschemaekers, G. (2009). Musicassisted relaxation to improve sleep quality: Meta-analysis. Journal of Advanced Nursing, 65(7), 1356-1364. doi:10.1111/j.1365-2648.2009.04982.x

DeNora, T. (2000). Music in everyday life. Cambridge, UK: Cambridge University Press.

Dunkel, C. S., \& Weber, J. L. (2010). Using three levels of personality to predict time perspective. Current Psychology, 29, 95-103. doi:10.1007/s12144-010-9074-x

Fields, B., \& Lamere, P. (2010). Finding a path through the juke box: The playlist tutorial. Paper presented at the 11th International Society for Music Information Retrieval Conference (ISMIR), August 9-13, 2010.

Garrido, S., \& Schubert, E. (2015). Moody melodies: Do they cheer us up? A study of the effect of sad music on mood. Psychology of Music, 43(2), 244-261. doi:10.1177/0305735613501938

Gellert, P., Ziegelmann, J. P., Lippke, S., \& Schwarzer, R. (2012). Future time perspective and health behaviors: Temporal framing of self-regulatory processes in physical exercise and dietary behaviors. Annals of Behavioral Medicine, 43, 208-218. doi:10.1007/s12160-011-9312-y 
Hall, P. A., \& Fong, G. T. (2003). The effects of a brief time perspective intervention for increasing physical activity among young adults. Psychology and Health, $18(6), 685-706$.

Hall, P. A., Fong, G. T., Yong, H.-H., Sansone, G., Borland, R., \& Siahpush, M. (2012). Do time perspective and sensation-seeking predict quitting activity among smokers? Findings from the International Tobacco Control (ITC) four country survey. Addictive Behaviors, 37(1307-1313).

doi:10.1016/j.addbeh.2012.06.022

Holman, E. A., \& Zimbardo, P. G. (2009). The social language of time: The time perspective-social network connection. Basic and Applied Social Psychology, 31(2), 136-147. doi:10.1080/01973530902880415

Hu, X. (2010). Music and mood: Where theory and reality meet. In the Proceedings of the 5th iConference, Feb. 2010. University of Illinois at UrbanaChampaign, Champaign, IL.

Kahana, E., Kahana, B., \& Zhang, J. (2005). Motivational antecedents of preventive proactivity in late life: Linking future orientation and exercise. Motivation and Emotion, 29(4), 438-459. doi:10.1007/s11031-006-9012-2

Kamalzadeh, M., Baur, D., \& Möller, T. (2012). A survey on music listening and management behaviours. In Proceedings of the 13th International Society for Music Information Retrieval Conference (ISMIR 2012), Porto, Portugal.

Keough, K. A., Zimbardo, P. G., \& Boyd, J. N. (1999). Who's smoking, drinking, and using drugs? Time perspective as a predictor of substance use. Basic and Applied Social Psychology, 21(2), 149-164.

Kibby, M. (2009). Collect yourself: Negotiating personal archives. Information, Communication, \& Society, 12(3), 428-443. doi:10.1080/13691180802660644 
Komulainen, S., Karukka, M., \& Hakkila, J. (2010). Social music services in teenage life - A case study. In S. Viller \& B. Kraal (Eds.) Proceedings of the 22nd Conference of the Computer-Human Interaction Special Interest Group of Australia on Computer-Human Interaction, OZCHI'10, November 22-26, 2010, 364-367. doi:10.1145/1952222.1952303

Krause, A. E. (2010). myTunes: Digital music library users and their self images. (MA Applied Music Psychology), Roehampton Unversity.

Krause, A. E., \& North, A. C. (2014). Contextualized music listening: Playlists and the Mehrabian and Russell model. Psychology of Well-Being: Theory Research and Practice.

Krause, A. E., \& North, A. C. (2016). Music listening in everyday life: Devices, selection methods, and digital technology. Psychology of Music, 44, 1, 129147. doi:10.1177/0305735614559065

Krause, A. E., North, A. C., \& Hewitt, L. Y. (2014). Music selection behaviors in everyday listening. Journal of Broadcasting and Electronic Media, 58(2), 306-323. doi:10.1080/08838151.2014.906437

Laghi, F., Liga, F., Baumgartner, E., \& Baiocco, R. (2012). Time perspective and psychosocial positive functioning among Italian adolescents who binge eat and drink. Journal of Adolescence, 35, 1277-1284. doi:10.1016/j.adolescence.2012.04.014

Lamont, A., \& Greasley, A. E. (2009). Musical preferences. In S. Hallam, I. Cross, \& M. Thaut (Eds.), The oxford handbook of music psychology (pp. 160-168). Oxford: Oxford University Press. 
Lang, F. R., \& Carstensen, L. L. (2002). Time counts: Future time perspective, goals, and social relationships. Psychology and Aging, 17(1), 125-139. doi:10.1037//0882-7974.17.1.125

Lee, J. H., \& Cunningham, S. J. (2013). Toward an understanding of the history and impact of user studies in music information retrieval. Journal of Intelligent Information Systems, 41, 499-521. doi: 10.1007/s10844-013-0259-2

Leong, T. W., Vetere, F., \& Howard, S. (2008). Abdicating choice: The rewards of letting go. Digital Creativity, 19(4), 233-243. doi:10.1080/14626260802550777

Mann, T. (2001). Effects of future writing and optimism on health behaviors in HIV infected women. Annals of Behavioral Medicine, 23(1), 26-33.

McInerney, D. M. (2004). A discussion of future time perspective. Educational Psychology Review, 16(2), 141-151. doi:1040-726X/04/0600-0141/0

Mello, Z. R., \& Worrell, F. C. (2006). The relationship of time perspective to age, gender, and academic achievement among academically talented adolescents. Journal for the Education of the Gifted, 29, 3, 271-289.

Molteni, L., \& Ordanini, A. (2003). Consumption patterns, digital technology and music downloading. Long Range Planning, 36(4), 389-406. doi:10.1016/S0024-6301(03)00073-6

North, A. C., \& Hargreaves, D. J. (1996). Situational influences on reported musical preference. Psychomusicology, 15, 30-45.

Orbell, S., \& Kyriakaki, M. (2008). Temporal framing and persuasion to adopt preventive health behavior: Moderating effects of individual differences in consideration of future consequences on sunscreen use. Health Psychology, 27(6), 770-779. doi:10.1037/0278-6133.27.6.770 
Saarikallio, S. (2008). Music in mood regulation: Initial scale development. Musicae Scientiae, 12(2), 291-309.

Seijts, G. H. (1998). The importance of future time perspective in theories of work motivation. Journal of Psychology, 132(2), 154-168.

Stolarski, M., Matthews, G., Postek, S., Zimbardo, P. G., \& Bitner, J. (2014). How we feel is a matter of time: Relationships between time perspectives and mood. Journal of Happiness Studies, 15, 809-827. doi: 10.1007/s10902-013-9450-y

Stumpf, S., \& Muscroft, S. (2011). When users generate music playlists: When words leave off, music begins? In Proceedings of ICME 2011, pp. 1-6.

Zhang, J. W., \& Howell, R. T. (2011). Do time perspectives predict unique variance in life satisfaction beyond personality traits? Personality and Individual Differences, 50, 1261-1266. doi:10.1016/j.paid.2011.02.021

Zimbardo, P. G., \& Boyd, J. N. (1999). Putting time in perspective: A valid, reliable individual-differences metric. Journal of Personality and Social Psychology, $77(6), 1271-1288$.

Zimbardo, P. G., Keough, K. A., \& Boyd, J. N. (1997). Present time perspective as a predictor of risky driving. Personality \& Individual Differences, 23(6), 10071023. 
Table 1.

Sample Means, Standard Deviations, and Correlations for Playlist Behaviors and Time Perspective $(N=201)$

\begin{tabular}{|c|c|c|c|}
\hline \multirow[b]{4}{*}{ Variable } & & & \multirow{3}{*}{$\begin{array}{l}\text { Pearson } \\
\text { Correlation } \\
\text { Coefficient }\end{array}$} \\
\hline & \multirow{2}{*}{\multicolumn{2}{|c|}{$\begin{array}{c}\text { Descriptive } \\
\text { statistic }\end{array}$}} & \\
\hline & & & \\
\hline & $M$ & $S D$ & Age \\
\hline How often do you listen to music via playlists? & 4.60 & 1.86 & $-.21 * *$ \\
\hline \multicolumn{4}{|l|}{ Playlist type } \\
\hline Based on a music artist/ group & 4.22 & 1.78 & $-.19 * *$ \\
\hline Based on a genre & 4.64 & 1.97 & -.14 \\
\hline Based on a specific situation or activity & 4.84 & 1.82 & $-.20 * *$ \\
\hline Based on a feeling/ emotion/mood & 4.88 & 2.00 & $-.27 * * *$ \\
\hline Based on time (holiday, season, etc.) & 4.36 & 2.03 & $-.21 * *$ \\
\hline For a house party with friends & 5.02 & 1.90 & $-.24 * * *$ \\
\hline For commuting on public transportation & 3.63 & 2.03 & $-.15 *$ \\
\hline To use while doing the washing up/ ironing & 2.84 & 1.79 & -.10 \\
\hline To listen to before going to sleep & 3.38 & 2.15 & $-.16 *$ \\
\hline For a posh cocktail reception & 2.02 & 1.38 & -.06 \\
\hline To listen to after a long day of work & 3.24 & 1.98 & $-.19 * *$ \\
\hline For a wedding & 2.45 & 1.85 & .05 \\
\hline To use while jogging with an mp3 player & 4.51 & 2.10 & $-.17 *$ \\
\hline \multicolumn{4}{|l|}{ Time perspective } \\
\hline FTP & 41.99 & 6.80 & -0.08 \\
\hline PTP & 25.96 & 4.60 & -0.13 \\
\hline
\end{tabular}


Note. Playlist items rated on a 1-7 scale. FTP scores ranged from 24 to 64 (of a possible 13 to

91) and PTP scores ranged from 13 to 37 (of a possible 9 to 63).

$* p<.05, * * p<.01, * * * p<.001$ 
Table 2.

Unstandardized (B) and Standardized ( $\beta$ ) Regression Coefficients, and Squared Semi-Partial Correlations (sr2) For Each Predictor Variable in

Hierarchical Multiple Regression Analyses Considering PTP and FTP Scores

\begin{tabular}{|c|c|c|c|c|c|c|c|c|c|c|c|c|}
\hline \multirow{3}{*}{$\begin{array}{l}\text { Mod } \\
1\end{array}$} & \multirow{3}{*}{$\begin{array}{l}\text { Playlist type } \\
\text { Based on a music artist/ group }\end{array}$} & \multicolumn{5}{|c|}{ FTP } & \multicolumn{6}{|c|}{$P T P$} \\
\hline & & \multirow{2}{*}{$\begin{array}{l}\mathrm{B} \\
0.20\end{array}$} & \multicolumn{2}{|c|}{$95 \% \mathrm{CI}$} & \multirow{2}{*}{$\begin{array}{l}\beta \\
0.05\end{array}$} & \multirow{2}{*}{$\begin{array}{l}\mathrm{sr}^{2} \\
.002\end{array}$} & \multirow{2}{*}{$\begin{array}{l}\mathrm{B} \\
0.24\end{array}$} & \multicolumn{2}{|c|}{$95 \% \mathrm{CI}$} & & \multirow{2}{*}{$\begin{array}{l}\beta \\
0.09\end{array}$} & \multirow{2}{*}{$\begin{array}{l}\mathrm{sr}^{2} \\
.007\end{array}$} \\
\hline & & & -0.39 & 0.79 & & & & -0.14 & 0.62 & & & \\
\hline & Based on a genre & 0.00 & -0.59 & 0.58 & 0.00 & .000 & 0.17 & -0.21 & 0.54 & & 0.07 & .003 \\
\hline & Based on a specific situation or activity & 0.00 & -0.71 & 0.71 & 0.00 & .000 & 0.63 & 0.17 & 1.08 & $* *$ & 0.25 & .034 \\
\hline & Based on a feeling/ emotion/mood & 0.36 & -0.24 & 0.95 & 0.11 & .007 & 0.00 & -0.39 & 0.38 & & 0.00 & .000 \\
\hline & Based on time (holiday, season, etc.) & -0.16 & -0.74 & 0.43 & -0.05 & .001 & -0.05 & -0.42 & 0.33 & & -0.02 & .000 \\
\hline \multicolumn{2}{|c|}{$R^{2}$} & \multicolumn{5}{|l|}{0.01} & \multicolumn{6}{|l|}{0.10} \\
\hline \multicolumn{2}{|c|}{$F(5,193)$} & \multicolumn{5}{|c|}{$0.47, p=.800$} & \multicolumn{6}{|c|}{$4.107, p=.001$} \\
\hline \multirow[t]{3}{*}{2} & Based on a music artist/ group & 0.05 & -0.58 & 0.67 & 0.01 & .000 & 0.18 & -0.22 & 0.57 & & 0.07 & .003 \\
\hline & Based on a genre & 0.08 & -0.49 & 0.66 & 0.02 & .000 & 0.03 & -0.33 & 0.40 & & 0.01 & .000 \\
\hline & Based on a specific situation or activity & -0.37 & -1.12 & 0.39 & -0.10 & .004 & 0.93 & 0.45 & 1.40 & $* * *$ & 0.37 & .063 \\
\hline
\end{tabular}




\begin{tabular}{|c|c|c|c|c|c|c|c|c|c|c|c|c|}
\hline Based on a feeling/ emotion/mood & 0.37 & -0.25 & 0.99 & & 0.11 & .007 & -0.18 & -0.57 & 0.21 & & -0.08 & .003 \\
\hline Based on time (holiday, season, etc.) & -0.05 & -0.65 & 0.56 & & -0.01 & .000 & -0.23 & -0.61 & 0.15 & & -0.10 & .006 \\
\hline For a house party with friends & -0.33 & -0.93 & 0.27 & & -0.09 & .006 & 0.28 & -0.10 & 0.65 & & 0.12 & .009 \\
\hline For commuting on public transportation & 0.29 & -0.32 & 0.90 & & 0.09 & .004 & 0.22 & -0.17 & 0.60 & & 0.10 & .005 \\
\hline To use while doing the washing up/ ironing & -0.16 & -0.90 & 0.58 & & -0.04 & .001 & 0.06 & -0.41 & 0.52 & & 0.02 & .000 \\
\hline To listen to before going to sleep & -0.38 & -0.92 & 0.15 & & -0.12 & .010 & 0.51 & 0.17 & 0.84 & $* *$ & 0.24 & .037 \\
\hline For a posh cocktail reception & -0.19 & -1.11 & 0.74 & & -0.04 & .001 & 0.01 & -0.58 & 0.59 & & 0.00 & .000 \\
\hline To listen to after a long day of work & 0.79 & 0.18 & 1.41 & $*$ & 0.23 & .031 & -0.33 & -0.72 & 0.06 & & -0.14 & .012 \\
\hline For a wedding & -0.38 & -1.04 & 0.29 & & -0.10 & .006 & 0.42 & 0.00 & 0.84 & & 0.17 & .016 \\
\hline To use while jogging with an mp3 player & 0.64 & 0.10 & 1.18 & $*$ & 0.20 & .027 & -0.59 & -0.93 & -0.25 & $* *$ & -0.27 & .050 \\
\hline & 0.11 & & & & & & 0.21 & & & & & \\
\hline 85) & \multicolumn{6}{|c|}{$2.46, p=.015$} & \multicolumn{5}{|c|}{$3.45, p=.001$} & \\
\hline
\end{tabular}

Note. ${ }^{*} p<.05, * * p<.01,{ }^{* * *} p<.001$. 